\title{
Vivienda y ciudad
}

Housing and city

Michelle Bachelet Jeria

\section{Filiación}

Presidenta de la República de Chile

\section{Resumen}

Extracto del discurso de S.E., la Sra. Presidenta de la República de Chile, Dra. Michelle Bachelet Jeria, en Valparaíso el 21 de mayo de 2006, en lo referido a Vivienda y Ciudad.

\section{Palabras clave}

Michelle Bachelet Jeria; Discurso presidencial del 21 de mayo de 2006; Vivienda y ciudad.

\section{Abstract}

Extract from the speech of H.E. the President of the Republic of Chile, Dr. Michelle Bachelet Jeria in Valparaiso on May 21, 2006, with regard to Housing and Town.

\section{Key words}

Michelle Bachelet Jeria; The presidential address of May 21, 2006; Housing and city

\section{Sumario}

[Extracto de 10 párrafos]

Fuente

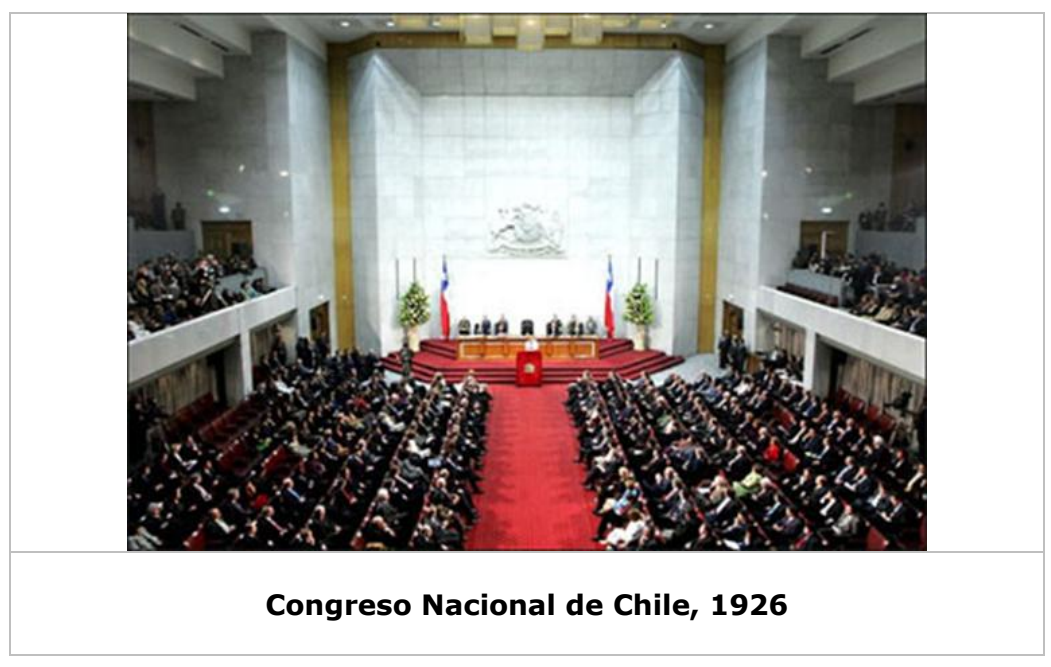

"Queremos ciudades amables. Que la gente las sienta propias, respetuosas de su patrimonio. Nuestra política urbana se orienta hacia la calidad de vida y la equidad territorial. 
Lo primero tiene que ver con la construcción de viviendas. Hemos construido más de un millón y medio de viviendas en los últimos 16 años. Ahora aplicaremos una estrategia que ponga en su centro la calidad de lo que se construye y revierta la segregación social.

¿Cómo lo haremos? Eliminaremos campamentos y ayudaremos a los allegados. Pondremos todo nuestro esfuerzo en reducir drásticamente el déficit de vivienda del 20 por ciento más pobre de la población. Este será un desafío principal de mi gobierno.

Mejoraremos los estándares de calidad. iQueremos casas que no se lluevan en invierno, ni que tengan daños estructurales al cabo de un par de años! Vamos a fortalecer la legislación y la fiscalización para garantizar la calidad de lo que se construya.

Aceleraremos los programas de reparación de viviendas. iY aquellas casas que no pueden repararse, las demoleremos y construiremos otras nuevas! Eso es lo que merecen los ciudadanos. También aceleraremos las reparaciones de los inmuebles afectados por el terremoto en el Norte Grande.

Queremos mejores viviendas. Aumentaremos la superficie mínima de las viviendas nuevas. $Y$ apoyaremos a las familias que quieran ampliar sus casas y departamentos. iPorque queremos garantizar condiciones dignas para todas las personas!

Y lo más importante: mejoraremos el entorno en que vivimos los chilenos. En los últimos 16 años hemos estado abocados fundamentalmente a construir viviendas por el gran déficit que teníamos. Ahora nos centraremos en construir barrios. Queremos barrios seguros, iluminados, con áreas verdes y con espacios para el deporte y la vida al aire libre. Más plazas y más parques. Repararemos calles y veredas. Eliminaremos micro-vertederos $y$ estimularemos los programas de limpieza $y$ aseo. Los chilenos tenemos el derecho de vivir en vecindarios más acogedores.

Y de ningún modo me olvido de la clase media. He instruido a la Ministra de Vivienda para que perfeccione el subsidio habitacional dirigido a quienes, estando sobre la línea de la pobreza, no pueden obtener el crédito hipotecario. También vamos a incentivar la adquisición de viviendas usadas, como una manera de diversificar la oferta inmobiliaria hacia la clase media.

Recuperaremos los barrios consolidados que con el paso del tiempo se han ido deteriorando. Es una de las 36 medidas. Se trata de ir abordando, con creatividad y participación activa de los vecinos, las acciones necesarias para mejorar las condiciones de 200 barrios en todo Chile.

Esta tarea irá de la mano con la política de recuperación de barrios patrimoniales. Ya lo dije aquí mismo, hace unos días atrás en Valparaíso: tenemos la responsabilidad con Chile y el mundo de cuidar nuestro patrimonio, nuestra identidad. Para ello destinaremos, tanto los subsidios de renovación urbana, como los proyectos de recuperación patrimonial.

Queremos ciudades bellas, amables, equitativas. Esto supone una política urbana moderna, con sentido del territorio. Supone fortalecer la legislación e incorporar las 
REVISTA DE

URBANISMO

ISSN 0717-5051

http://revistas.uchile.cl/index.php/RU/index

Revista de Urbanismo N`14 - Junio de 2006 Departamento de Urbanismo - FAU - Universidad de Chile

variables ambientales y de integración social en los instrumentos de planificación territorial".

\section{Fuente}

http://www.presidencia.cl 